\title{
The Empirical Analysis on the Effect of Information Service for Developing Modern Agriculture
}

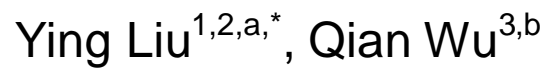 \\ ${ }^{1}$ Economic College, Wuhan Donghu University, Wuhan Hubei, 430212, China \\ ${ }^{2}$ Agricultural E-commerce Collaborative Innovation Center (Cultivation) in Hubei Province, Wuhan \\ Hubei, 430212, China \\ ${ }^{3}$ Economics and Management College, Hainan University, Haikou Hainan, 570228, China \\ ahelen1982117@sina.com, bwu.qiana@163.com \\ ${ }^{*}$ Corresponding author
}

Keywords: Information services, Modern agriculture, Influential effect.

\begin{abstract}
Based on the interactive-relationship analysis of Chinese information services and the development of modern agriculture, the paper uses the Eviews6.0 to empirically analyze the effect of information services in modern agriculture. The result turns out that information services have a huge promoted impact on the development of modern agriculture. And the paper further puts forward some countermeasures and suggestions which aim to enhance China's information services' level.
\end{abstract}

\section{Introduction of concept}

\section{Information Services}

Information services are socio-economic behaviors that services providers use some professional strategies and contents to help users solve their problems. It's the specialized industries' syntheses which provide the society with information products, and uses modern science and technology such as computers and communication networks to collect, conduct, process, store, transfer, retrieve and utilize information. Information services are the key to develop information resources and achieve commercialization, marketization, socialization and specialization [1]. Information services belong to service industry, which in the scope of tertiary industry.

\section{Agricultural information services}

Agricultural information services not only have the general features of information services, but also have peculiarities of the development of agriculture. It refers to the process of collecting, collating, processing, transmitting and utilizing the nature, economic and social information about agriculture production, management, strategic decision making. The China's agriculture information center define that agriculture information services mean service institution centers on users' demand for agriculture information, then launch some services work include information collecting, producing, processing and transmitting [2].

\section{Modern agriculture}

Compared with traditional agriculture, modern agriculture is extensive application of modern science and technology, production and scientific management methods provided by modern industry. According to the nature and level of productivity division, modern agriculture is the latest stage in history of agriculture development. The essence is innovational industry of Science and technology, which is characterized by combination of production, supply, agricultural integration, high productiveness and high-efficiency, and based on the level of modern science and technology and its applications, modern industrial technology and equipment level, technology and modern management level, and the level of modern agro-processing technology, modern agricultural technology and its circulating levels. Modern agriculture especially extrude high-tech, high productiveness and industrial system characteristics [3]. 


\section{Analysis of the interactive relationship}

As a production factor, information services are imputed into agricultural production, promote agricultural division of refinement, promote agricultural industrialization and marketization, boost market competitiveness of agricultural products and increase farmers' income [4]. Currently, research on the interaction between theory and modern agriculture information service is not yet much. Information services include agricultural information services and non-agricultural information services, information services provide impetus and intellectual support for the development of agricultural production.

The interaction mechanisms between them can be mainly summarized as the following aspects: firstly, information services industry promotes the development of agro-industries, such as agricultural products logistics, rural finance and industry, rural recreation and tourism; secondly, the development of agro-industries led to demand for information services; thirdly, the relationship between information services sector and agricultural sector manifests itself as interaction, interdependence and common development; Fourthly, modern agriculture and agro-industry are integrate development, and information services guide technology and product innovation of other sectors. Meanwhile, as the major breakthrough in high-tech agriculture, traditional agriculture will gradually disappear, and there's a new blurry form of industry boundaries.(As shown in Figure 1)

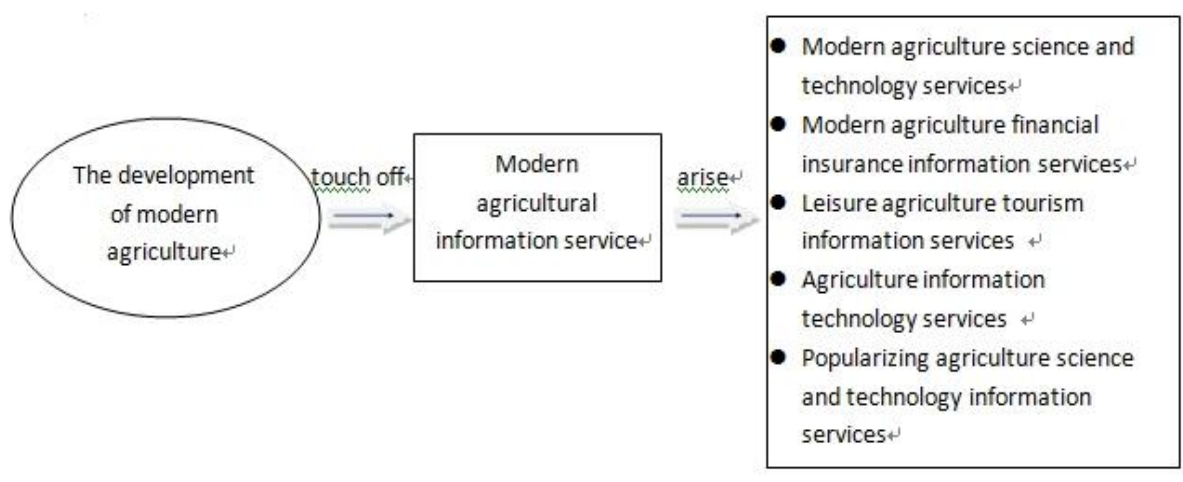

Fig. 1The interactive relationship

Hence, there exists a mutual promotion mechanism between the information services and the modern agriculture. However, the relationship between information services and the modern agriculture remains to be further explored. Following, based on the data of china, the writer will do a series of empirical research to analyze the effect of information services on modern agriculture.

\section{Empirical analysis}

The writer does empirical research based on the statistical data of china 1979-2013, so as to discuss the degree of correlation and interactive relationship between information services and modern agriculture.

\section{The output value tendency chart of agriculture and the tertiary industry}

Index Selection. Information Services (XXFW): The writer chooses china's tertiary industry gross domestic product as statistical indicator, information service as the independent variable. Selected time: 1979-2013.

Modern Agriculture (XDNY): The writer chooses china's agricultural GDP as statistical indicator, modern agriculture as dependent variable. Selected time: 1979-2013.

The particular form of model is as follows:

$$
(X D N Y)=\beta_{0}+\beta_{1}(X X F W)+\mu
$$

Among them, $\beta_{0}$ is the horizontal intercept of equation (1), $\beta_{1}$ is the elasticity coefficient of (XXFW), and $\mu$ is the residual.

In order to eliminate the heteroskedasticity, we take the form of logarithm each of the variable here, and get two new variables-LOG(XXFW) and LOG(XDNY). 
After that, we can modify the model as follows:

$$
L O G(X D N Y)=\beta_{0}+\beta_{1} L O G(X X F W)+\mu
$$

Among them, $\beta_{0}$ is the horizontal intercept of equation (2), $\beta_{1}$ is the elasticity coefficient of LOG(XXFW), and $\mu$ is the residual.

Tendency chart. Figure 2 indicates that information services and modern agriculture presents the same growth trend from 1979 to now. The growth trend of information services faster than the growth trend of modern agriculture. This trend indicates that since reform and opening up, with the development of science and technology, china's information service industry has made considerable progress. The development of modern agriculture was inferior to the information service. Two indicators show the same direction of movement relations, and the correlation may exist between them.

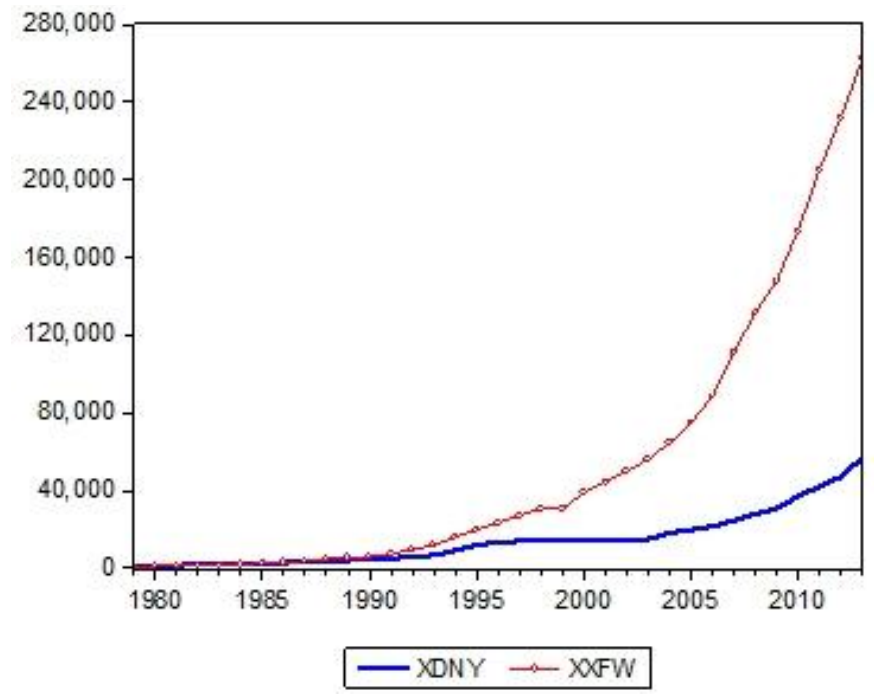

Source of information: Data processed by the related data over the years, which are issued by the People's Republic of China National Bureau of statistics index websites

Fig. 2 Tendency chart

\section{Estimation and test on model}

The author uses Eviens6.0 to evaluate two variables, and proceeds ADF unit root test, co-integration test, and Granger causality test.

ADF unit root test. The results of ADF unit root test of XXFW and XDNY are showed in table 1.

The ADF-T value of variable XDNY and LOG(XDNY) is 5\% higher than critical value, thus the original sequence of their time sequence is not stable. After the first order difference, ADF-T values of every variable in the table 1 were higher than the $5 \%$ critical value, so all variables are integrated of order 1 .

Tab. 1 The results of unit root test

\begin{tabular}{|l|c|l|l|c|l|l|}
\hline \multirow{2}{*}{ VARIABLE } & \multicolumn{3}{|c|}{ Level test results } & \multicolumn{2}{|c|}{ A first-order differential test results } \\
\cline { 2 - 7 } & ADF-T & $\begin{array}{l}5 \% \text { critical } \\
\text { value }\end{array}$ & conclusion & ADF-T & $\begin{array}{l}5 \% \text { critical } \\
\text { value }\end{array}$ & conclusion \\
\hline XXFW & -4.27 & -2.86 & steady & -10.95 & -2.86 & steady \\
\hline XDNY & -2.62 & -2.86 & Non-staionary & -9.78 & -2.86 & steady \\
\hline LOG(XXFW) & -4.10 & -2.86 & steady & -10.86 & -2.86 & steady \\
\hline LOG(XDNY) & -2.62 & -2.86 & Non-stationary & -9.91 & -2.86 & steady \\
\hline
\end{tabular}

Source of information: Data selected from the People's Republic of China National Bureau of Statistics' Website base data, calculated using Eviews5.0 
Co-integration test. The paper uses Johansen test method to test the co-integration relationship of LOG(XDNY) and LOG(XXFW) respectively. Johansen test results are shown in table 2. In order to determine whether there is co-integration relationship, we can judge form figures in the table 2 . If the first line of probability of Prob. ** (The value of $\mathrm{P}$ ) is less than the critical value of 0.05 , there is a co-integration relationship. Otherwise, the co-integration relationship isn't existed. The table 2 shows that the value of $\mathrm{P}$ is 0.048 , less than the critical value of 0.05 , and there are more significant co-integration relationship between LOG (XDNY) and LOG (XXFW). That is to say, they are not independent movement, but have certain long-term, stable relationship, and they show a common stochastic trend.

Tab. 2 Johansen test results

\begin{tabular}{|c|c|c|c|c|}
\hline \multirow{2}{*}{\multicolumn{5}{|c|}{$\begin{array}{l}\text { Date: 04/18/14 Time: 14: } 45 \\
\text { Sample (adjusted): } 19812013 \\
\text { Included observations: } 33 \text { after adjustments } \\
\text { Trend assumption: No deterministictrend } \\
\text { Series: LNXDNY LNXXFW } \\
\text { Lags interval (in first differences): } 1 \text { to } 1 \\
\text { Unrestricted Cointegration Rank Test (Trace) }\end{array}$}} \\
\hline & & & & \\
\hline $\begin{array}{l}\text { Hypothesized } \\
\text { No. of } C E(s)\end{array}$ & Ejgenvalue & $\begin{array}{l}\text { Trace } \\
\text { Statistic }\end{array}$ & $\begin{array}{l}0.05 \\
\text { Critical Value }\end{array}$ & Prob.** \\
\hline None & 0.289112 & 11.93317 & 12.32090 & 0.0480 \\
\hline At most 1 & 0.020165 & 0.672255 & 4.129906 & 0.4720 \\
\hline \multicolumn{5}{|c|}{$\begin{array}{l}\text { Trace test indicates } 1 \text { cointegratingegn(s) at the } 0.05 \text { level } \\
\text { * denotes rejection of the hypothesis at the } 0.05 \text { level }\end{array}$} \\
\hline
\end{tabular}

Source of information: Data selected from the People's Republic of China National Bureau of Statistics' Website base data, calculated using Eviews5.0

Granger causality test. Table 3 shows the existence of a co-integration relationship between the variables $\mathrm{LOG}(\mathrm{XNDY})$ and $\mathrm{LOG}(\mathrm{XXFW})$.To test whether this co-integration have real economic significance, we make the Granger causality test on two known variables LOG(XDNY) and LOG(XXFW) (Lag period of 2). Table 3 shows the test results. The results reveals that refusing "the LOG (XDNY) does not Granger cause LOG (XXFW)", but accepting "LOG (XXFW) does not cause LOG (XDNY)". It illustrates that the development of china's information is a possible reason for the development of modern agriculture since the reform and opening up, and modern agriculture failed to show a role in promoting the development of information services.

Tab. 3 Granger causality test

\begin{tabular}{|lllll|}
\hline Painwise Granger Causality Tests & & & \\
Date: $04 / 18 / 14 \quad$ Time: $15: 35$ & & & \\
Sample: 19792013 & & & \\
Lags: 2 & Obs & F-Statistic & Prob. \\
\hline \hline Null Hypothesis: & 33 & 4.24145 & 0.0246 \\
\hline \hline LOGXXFW does not Granger Cause LOGXDNY & 33 & & \\
LOGXDNY does not Granger Cause LOGXXFW & & 0.28603 & 0.7534 \\
\hline
\end{tabular}

Source of information: Data selected from the People's Republic of China National Bureau of Statistics" Website base data, calculated using Eviews5.0

\section{Conclusions and policy recommendations}

\section{Empirical Analysis Conclusion}

According to empirical analysis we have done above, and combining with China's actual situations, we can draw the following conclusions. 
Firstly, empirical studies show that China's information services growth greatly pull effect on modern agriculture, which shows further promotion of information services in china can adapt and push forward agricultural modernization development. Thus, in the lead in realizing modernization process, we must accelerate the pace of integration of modern agricultural information service development.

Secondly, the data show that the promoting effect of modern agriculture on information services is not obvious, mainly because the existing agricultural added value is notcounted through multi-functional agriculture. There are not recognized statistical methods and statistical outcome yet, and them remains to be scholars for further study.

\section{Policy recommendations}

Through empirical analysis, information services have a huge role in promoting the development of modern agriculture in China. Only to effectively improve the agricultural information service levels, to vigorously promote the development of modern agriculture. This analysis conclusion also prove that the correctness of "four steps synchronized approach" ("four steps" means Chinese characteristic new industrialization, informatization, urbanization, agricultural modernization), that proposed through the Eighteenth National Congress of the Communist Party of China. According to China's practical situation, the author proposes to proceed from the following aspects of reform, to promote the development of China's information services, and thus accelerate the development of modern agriculture.

First of all, the state should increase financial input and strengthen on information services infrastructure. To gradually establish of a regional economy centered on agriculture information service center, thus we can form a complete national agricultural information service network.

Secondly, we shall vigorously develop information services talent, and improve the recipient's ability to accept information service. Strengthen the training of modern information technology to government agricultural science and technology information workers, rural information service entity personnel, and new type agricultural management subject and farmer technician.

Finally, China shall reform existing agricultural information service system. Public information services and non public information services shall be developed commonly, and become mutual supplement. We shall make institutional reform to state-owned agricultural information services, carry out marketable, paid information services, and linked with the profits and benefits. Implement of preferential policies encourage and guide the development of semi-governmental and non-governmental of agricultural information services organizations.

\section{Acknowledgement}

This research was financially supported by the Youth Fund Project of Wuhan Donghu University. It is the staged achievements of the research subject, which name is Research on the innovation of agricultural science and technology communication system to cope with the changes of agricultural climate (Youth Fund Project of Wuhan Donghu University in 2014).

\section{References}

[1] He Zhong-wei, Jiang He-ping, Chan Yian Feng, Stage positioning and construction of modern agricultural development strategy [J], Beijing Institute of Electronic Science and Technology, 2004 (3): 11-14.

[2] Li Ying Bo, China Agricultural Information Service System Development [M]. The chinese Economic Press, 2006(12).

[3] Zhang Xiao-fang, Modern agriculture demonstration area of agricultural information service systems[D]. Hubei: Huazhong Agricultural University, 2013.

[4] Chen Junhhong, Wang Ailing, Zhou Liandi, The Status and innovative model of Beijing Agricultural Technology Service System Development [J] Agricultural Economics, 2010 (3): 42-45. 